\title{
Culturas inclusivas en educación media superior: construcción y validación de instrumentos
}

\section{Inclusive cultures in secondary education: Construction and validation of instruments}

\section{Gabriela DE LA CRUZ Flores*}

El objetivo del estudio fue elaborar y validar instrumentos para la promoción de culturas inclusivas en educación media superior (EMS). Se entiende por culturas inclusivas aquellas que reconocen la diversidad, favorecen el aprendizaje y la participación, construyen comunidad y fortalecen el sentido de pertenencia. A partir de la revisión de la literatura y el trabajo de campo en planteles de EMS, se elaboró una escala de respuesta tipo Likert dirigida a estudiantes y una guía de trabajo para la mejora de las culturas inclusivas en colectivos escolares. La escala fue validada con análisis factoriales que dieron como resultado cinco factores: responsabilidad con el aprendizaje y sentido de pertenencia; ambiente escolar afectivo; construcción social del conocimiento; desarrollo de ciudadanía y participación social; y seguridad escolar y sus entornos. La escala, en su conjunto, obtuvo una alta consistencia interna ( $\alpha$.92) y explica el 51\% de la varianza. Luego de su validación, se elaboró una guía que establece fases y preguntas que convocan a estudiantes, docentes y autoridades a construir proyectos en común para la generación de culturas inclusivas. Ambos instrumentos fueron diseñados considerando la heterogeneidad del subsistema de EMS en México.

The objective of this research was to develop and validate tools for the promotion of inclusive cultures in secondary education. Inclusive cultures are understood as those that recognize diversity, encourage learning and participation, build community, and strengthen the sense of belonging. Based on a review of the literature and field work at secondary schools, a Likert-type scale was developed for students and a guide for the improvement of inclusive cultures in school groups was established. The scale was validated through factor analysis resulting in five factors: Responsibility with learning and sense of belonging; Affective school environment; Social construction of knowledge; Development of citizenship and social participation and Safety in school and its surroundings. The scale obtained a high internal consistency ( $\alpha .92)$ and explains 51\% of the variance. After the scale was validated, a guide was prepared establishing phases and questions that call on students, teachers, and authorities to build common projects for the generation of inclusive cultures. Both instruments were designed considering the heterogeneity of the subsystem in Mexico.

\section{Palabras clave:}

culturas inclusivas, educación media, inclusión educativa, jóvenes

\section{Keywords:}

inclusive culture, secondary education, educational inclusion, youth

Recibido: 8 de junio de 2020 | Aceptado para su publicación: 23 de noviembre de 2020 | Publicado: 30 de enero de 2021

Recuperado de: https://sinectica.iteso.mx/index.php/SINECTICA/article/view/1159 doi: 10.31391/S2007-7033(2021)0056-006

\footnotetext{
* Doctora en Psicología. Investigadora del Instituto de Investigaciones sobre la Universidad y la Educación de la Universidad Nacional Autónoma de México. Líneas de investigación: inclusión-exclusión en educación media, abandono y retorno escolar, formación continua del profesorado, tutoría en educación superior y evaluación educativa. Correo electrónico: gabydc@unam.mx
} 


\section{INTRODUCCIÓN}

7 ste artículo forma parte de una línea de investigación sobre culturas escolares

- en educación media superior (EMS) e inclusión educativa. Esta línea ha tenido como unidad de análisis e intervención planteles de EMS situados en la Ciudad de México, correspondientes al bachillerato general y al profesional técnico. La indagación situada y contextual basada en los métodos etnográfico y fenomenológico nos ha permitido identificar de manera recurrente prácticas y procesos de exclusión incluyente, tal como Gentili (2009) definió los mecanismos y las dinámicas de inclusión que acaban "resultando insuficientes o, en algunos casos, inocuas para revertir los procesos de aislamiento, marginación y negación de derechos que están involucrados en todo proceso de segregación social, dentro y fuera de las instituciones educativas" (p. 33).

Así, estudiantes de EMS pueden cohabitar los espacios escolares sin desplegar plenamente sus capacidades de intervención y participación, lo cual nos ha llevado a cuestionar el papel de las culturas escolares en el fomento de la inclusión. Lo anterior coincide con investigaciones que han documentado y teorizado desencuentros entre la cultura escolar y las culturas juveniles, en las que se afirma que la primera con frecuencia impide que los jóvenes se acerquen al conocimiento y logren proyectarse en el plano social y político (Gutiérrez-Castro, 2015).

Si bien el concepto de inclusión educativa posee distintos significados, recuperamos la aproximación que Echeita (2013) ofrece al respecto:

... la inclusión educativa no es sólo un sentimiento de pertenencia y de bienestar emocional y relacional al que se pueda llegar desde la periferia de la acción educativa. La inclusión educativa debe entenderse con igual fuerza como la preocupación por un aprendizaje y un rendimiento escolar de alta calidad y exigente con las capacidades de cada estudiante. Por otra parte, la vida escolar en la que todos los alumnos deben sentirse incluidos transcurre a través de las actividades de enseñanza y aprendizaje con sus iguales y no al margen de ellas, y porque la mejor contribución de la educación escolar a la inclusión social de cualquiera es poder alcanzar el mayor nivel de logro y de cualificación escolar posible [...]. También podría decirse que es pensar y revisar hasta qué punto el currículo escolar, en toda su amplitud de significados, se configura o no, como un proceso facilitador u obstaculizador del aprendizaje y el rendimiento de todos los alumnos... (p. 107).

Los aportes de Echeita al constructo inclusión educativa nos permiten tasar el peso de las culturas escolares en el impulso de la inclusión, en la que se reconoce y afianza el sentido de pertenencia a la par de que se promueve, de manera deliberada, el aprendizaje, el logro y el éxito de todos los estudiantes que redunden en su inclusión social. El índex de la inclusión liderado por Booth y Ainscow y sus diferentes versiones coinciden en definir las culturas inclusivas como aquellas que promueven comunidades seguras, acogedoras, colaboradoras, donde cada integrante es valorado y se fomentan mayores niveles de logro, para lo cual se comparten y transmiten valores inclusivos que permean las actividades de todos los miembros de la comunidad escolar.

En aras de diseñar herramientas que contribuyan a valorar y alentar la construcción y el desarrollo de culturas inclusivas en planteles de EMS, en las siguientes páginas presentamos dos instrumentos elaborados en el marco de la línea de investigación ya referida. El primero es una escala de respuesta tipo Likert denominada "Culturas inclusivas en EMS", cuyo propósito es explorar las valoraciones de estudiantes sobre 
la naturaleza inclusiva de las culturas escolares de sus planteles. Para su construcción, a partir de la revisión de la literatura, definimos el constructo cultura inclusiva y detallamos indicadores e ítems específicos, que validamos a través de análisis factoriales que dieron como resultado cinco factores: responsabilidad con el aprendizaje y sentido de pertenencia; ambiente escolar afectivo; construcción social del conocimiento; desarrollo de ciudadanía y participación social; y seguridad escolar y sus entornos. La escala, en su conjunto, obtuvo una alta consistencia interna ( $\alpha$.92) y explica el $51 \%$ de la varianza.

Por su parte, la guía "Promoción de culturas inclusivas: construcción de proyectos comunes" ofrece una ruta de trabajo para orientar los esfuerzos de las comunidades escolares en pro de la inclusión. Cabe señalar que ambos instrumentos fueron diseñados considerando la heterogeneidad de la EMS en nuestro país, sin renunciar a los atributos clave que favorecen la construcción y el desarrollo de culturas inclusivas.

Los instrumentos expuestos son complementarios tanto en su contenido como en su uso. En cuanto a su contenido, la construcción y validación psicométrica de la escala permitió, de manera empírica, caracterizar el constructo cultura inclusiva que usamos como referente para la elaboración de la guía. Sobre su uso, es recomendable que, en un primer momento, se utilice la escala para analizar las valoraciones de estudiantes sobre la cultura escolar de los planteles de referencia y, en un segundo momento posterior al análisis de los resultados de la aplicación de la escala, se discuta, ajuste e implemente la guía como un instrumento de trabajo que promueva la colaboración entre los colectivos escolares hacia la mejora, la construcción y el desarrollo de culturas inclusivas.

Cabe señalar que las versiones del índex de la inclusión de Booth y Ainscow y los instrumentos elaborados ex profeso guardan similitudes, pero también diferencias. En cuanto a las similitudes, hemos recuperado la definición de cultura inclusiva, así como parte de la metodología de trabajo al interior de los centros escolares en tanto se convoca a las comunidades a reflexionar y transformar las culturas escolares basadas en valores inclusivos. Por su parte, las diferencias se concentran en los siguientes rubros: los instrumentos fueron realizados considerando la naturaleza de la EMS (el índex se concentra en educación básica); la construcción y validación de una escala sobre culturas inclusivas dirigida a estudiantes de EMS; la definición de dimensiones sustentadas en evidencia empírica; y la construcción y validación de una guía para la promoción de culturas inclusivas en EMS.

Tanto la escala como la guía se justifican porque diagnósticos nacionales sobre la situación que guardan los planteles de EMS han identificado problemas recurrentes que interpelan la naturaleza de las culturas escolares; por ejemplo, el Instituto Nacional para la Evaluación de la Educación (INEE, 2018), en un estudio sobre las condiciones básicas para la enseñanza y el aprendizaje en los planteles de EMS, advirtió que apenas un $21 \%$ de los planteles hacen consultas para conocer la opinión de los estudiantes sobre temas relacionados con estos, y un escaso 15\% reportó participación de los estudiantes en las decisiones de mejora de los planteles; ambos aspectos tienen que ver con las culturas escolares y su capacidad para fomentar la participación y el sentido de pertenencia de los estudiantes.

En cuanto a seguridad, se reportó que un $87 \%$ del estudiantado se siente seguro dentro de sus planteles. Sin embargo, llama la atención la percepción menguada de 
la seguridad en los alrededores de aquellos. Esto último, denota áreas de intervención a fin de generar culturas inclusivas que promuevan condiciones que brinden seguridad a cada estudiante para convivir, aprender y desarrollarse.

El artículo se divide en cuatro secciones. En el marco teórico analizamos el constructo de cultura inclusiva y lo articulamos con el enfoque de eficacia escolar. La sección referente al método se divide en dos grandes fases: construcción y validación psicométrica de la escala "Culturas inclusivas en EMS" para estudiantes, y validación de la guía "Promoción de culturas inclusivas: construcción de proyectos comunes", dirigida a centros escolares de EMS. En la tercera sección presentamos y discutimos los resultados; de la escala, resaltamos su alta confiabilidad y validez, y de la guía, su factibilidad y pertinencia para promover el trabajo colaborativo. Finalmente, en la discusión y las conclusiones profundizamos sobre la naturaleza inclusiva de los instrumentos expuestos y abrimos nuevas áreas de intervención, las cuales apuntalan la importancia de perfilar la inclusión como parte de un proceso cuyo centro sea el aprendizaje y el desarrollo pleno y digno de todos los agentes escolares.

\section{MARCO TEÓRICO}

Desde la década de los noventa y con el impulso de esfuerzos encabezados por la Organización de las Naciones Unidas para la Educación, la Ciencia y la Cultura (Unesco), se ha avanzado hacia la conformación de políticas y modelos educativos sustentados en la inclusión. Lo anterior ha tenido varias implicaciones, entre otras: afianzar las acciones para ejercer el derecho a la educación y al aprendizaje; reducir toda clase de marginación y exclusión, sea por condición social, racial, étnica, de género o discapacidad; alentar la construcción de sociedades más justas y equitativas; y reconocer la diversidad como principio articulador y estructurante de la actividad educativa. Lo descrito queda de manifiesto en la Agenda para el Desarrollo Sostenible 2030 (Unesco, 2015), cuyo objetivo 4 refiere: “Garantizar una educación inclusiva, equitativa y de calidad y promover oportunidades de aprendizaje durante toda la vida para todos".

En el ámbito de las políticas educativas (Unesco, 2009), se ha hecho evidente la importancia de impulsar sistemas educativos que garanticen el derecho a la educación y que orienten sus esfuerzos al reconocimiento de la diversidad mediante planes y métodos de enseñanza y aprendizajes flexibles; reorientación de la formación docente; acogida favorable de la diversidad; participación de los padres y las comunidades; y atención de posibles barreras para el aprendizaje y opciones para afrontarlas; es decir, sistemas educativos que asuman la inclusión como parte de un proceso que contribuye a la consolidación de sociedades donde la diversidad sea la constante. Esta premisa tiene grandes implicaciones, ya que estamos frente a un cambio radical en el cual la diferencia no significa ser marginal, sino se sitúa como un valor que reconfigura las estructuras sociales.

Para Infante (2010), el origen del concepto y las prácticas de inclusión educativa se ubican en movimientos sociales que pugnaron por los derechos de las personas con discapacidad. De manera paulatina, tanto el concepto como las prácticas se han ampliado hacia aproximaciones que ponderan el reconocimiento de la diversidad en los sistemas educativos regulares y, con ello, la heterogeneidad en los procesos 
de aprendizaje y la construcción de identidades. En palabras de Infante (2010): “Se amplía así la representación de quiénes son los sujetos interpelados en y por esta nueva significación, abriendo espacios a nuevas subjetividades y a las intersecciones de sus marcadores (ej., discapacidad, etnia, género, entre otras)" (p. 288).

\section{INCLUSIÓN EDUCATIVA Y EDUCACIÓN MEDIA SUPERIOR}

¿Qué implica la inclusión educativa en EMS? Existen varias rutas para contestar esta pregunta. Una de ellas se acota al análisis de indicadores como la cobertura, en el que observamos progresiones considerables en nuestro país. Así por ejemplo, del ciclo 2000-2001 al 2017-2018 apreciamos un aumento del 114\% en la existencia de escuelas y un crecimiento del 77\% en la matrícula (Presidencia de la República, 2019). Sin embargo, esta mirada cuantitativa, e incluso eficientista, deja de lado el cuestionamiento sobre el alcance del ejercicio del derecho a la educación y al aprendizaje de todos independiente de sus puntos de origen y las desigualdades sociales. En este sentido, el problema de la inclusión no se restringe al acceso; implica crear entornos escolares que favorezcan el aprendizaje, la permanencia y el egreso exitoso de todos.

Por otra parte, la obligatoriedad de la EMS ha ampliado los perfiles de jóvenes provenientes de múltiples sectores $\mathrm{y}$, de manera concomitante, ha exacerbado problemas y dificultades, en particular para quienes han gozado de menores oportunidades a lo largo de sus trayectorias escolares. Dichas problemáticas han sido documentadas con detalle por autores como Román (2013) y Tenti (2000); este último señala lo siguiente:

Todas estas transformaciones en la demografía, la morfología y la cultura de las nuevas generaciones ponen en crisis la oferta tradicional de educación escolar. Los síntomas más manifiestos y estridentes son la exclusión y el fracaso escolar, el malestar, el conflicto y el desorden, la violencia y las dificultades de la integración en las instituciones, y sobre todo la ausencia de sentido de la experiencia escolar para proporciones significativas de adolescentes y jóvenes latinoamericanos (en especial aquellos que provienen de los grupos sociales más excluidos y subordinados) que tienen dificultades para ingresar, progresar y desarrollarse en instituciones que no han sido hechas para ellos. Todo pareciera indicar que todos aquellos que "llegan tarde" a la escuela (los adolescentes y jóvenes excluidos) ingresan a una institución ajena, y que por lo tanto no cumple ninguna función para sus proyectos vitales (p. 2).

Las mutaciones en la EMS y su innegable crecimiento tanto en México como en América Latina interpelan la discusión de fondo sobre el papel de las culturas escolares para albergar la diversidad de perfiles de estudiantes, y que no solo se les reconozca como jóvenes con sus múltiples lenguajes y formas de interactuar, sino que florezca un crisol de subjetividades a través de la participación y las propuestas educativas que forjen agencia con el aprendizaje, así como "conocimientos y actitudes complejas y necesarias para la inserción social y política de los jóvenes en el mundo adulto" (Tenti, 2000, p. 12). Lo anterior implica cuestionar el papel de currículo escolar en la promoción de experiencias educativas que redunden en el reconocimiento de la diversidad y abone al desarrollo de cada estudiante, al romper con esquemas homogéneos y estandarizados.

Para Arellano (2007), las escuelas requieren cierta mutación epistemológica para que tengan cabida los variados lenguajes con los que interactúan los jóvenes y se 
conviertan en espacios para el entrecruce "de saberes y narrativas que configuran las oralidades, las literalidades y las visualidades” (p. 84). Para Frandsen (2014), la falta de comprensión de estos múltiples lenguajes y símbolos a los que acceden los jóvenes puede abrir brechas y exclusión en el aprendizaje. De ahí la relevancia de articular la cultura escolar con las culturas de los jóvenes, ya que, con frecuencia, se muestran distantes e incluso en tensión (Feixa, 2010), lo cual dificulta el entrecruce de la experiencia escolar con "las perspectivas de los estudiantes en cuanto a sus dimensiones emocionales y experienciales desarrolladas en su cotidianidad" (Gutiérrez-Castro, 2015, p. 99).

La necesaria articulación entre la cultura escolar y las culturas juveniles desde el plano de las políticas educativas coincide con un punto de quiebre que, en su momento, el Instituto Nacional para la Evaluación de la Educación (INEE, 2017) identificó como una directriz para mejorar la permanencia del estudiantado; se refería a la urgencia de afianzar la identidad de los jóvenes con la escuela, a través de ambientes escolares seguros, incluyentes y democráticos, con el propósito de "promover un clima que favorezca el sentido de pertenencia de los jóvenes con su comunidad escolar para que en ella encuentren respeto, reconocimiento, seguridad, espacios de socialización, participación y altas expectativas de desarrollo académico y personal" (INEE, 2017, p. 43.).

Sin embargo, articular la cultura escolar con las culturas juveniles en la actualidad no solo evoca replanteamientos pedagógicos de fondo, sino transformar los procesos de formación desde la alteridad, como lo señala Muñoz (2009): "La alteridad como relación de apertura hacia el Otro en su diferencia radical, como fuente de la ética, como respuesta cultural al totalitarismo, al sectarismo, a la violencia y al poder como locura, que implican los procesos civilizatorios" (p. 363). Desde este planteamiento, la inclusión en el ámbito educativo se aprecia como un horizonte que requiere la transformación de la cultura y prácticas escolares que favorezcan la configuración de relaciones sustentadas en el reconocimiento de la diversidad.

\section{CULTURAS ESCOLARES DESDE EL ENFOQUE DE EFICACIA ESCOLAR}

El constructo de cultura escolar posee distintos significados, lo que hace compleja una definición unificada y consistente (Elías, 2015; Gálvez, 2006; Molina y Sandoval, 2006), como lo ejemplificamos en la tabla 1, que sintetiza diferentes definiciones.

Tabla 1. Ejemplos de definiciones del constructo cultura escolar

\begin{tabular}{|c|c|c|}
\hline Definición & Autor & Año \\
\hline $\begin{array}{l}\text { “... conjunto de significados, expectativas y comportamientos compar- } \\
\text { tidos por un determinado grupo social, que facilitan y ordenan, limitan } \\
\text { y potencian, los intercambios sociales, las producciones simbólicas y ma- } \\
\text { teriales y las realizaciones individuales y colectivas dentro de un marco } \\
\text { espacial y temporal determinado" }\end{array}$ & Pérez-Gómez & 2000 (p. 16) \\
\hline $\begin{array}{c}\text { “... comprende un conjunto de prácticas, saberes y representaciones pro- } \\
\text { ducidas y reproducidas a partir de la institución escolar. Pero también } \\
\text { incluye las modalidades de comunicación y transmisión de saberes para } \\
\text { poder actuar socialmente (más allá de la escuela) que operan de acuerdo } \\
\text { con la 'lógica' escolar. En este sentido, la cultura escolar es una forma } \\
\text { de producción, transmisión y reproducción que tiende a la organización } \\
\text { racional de la vida social cotidiana” }\end{array}$ & Huergo & 2001 (p. 92) \\
\hline
\end{tabular}

De la Cruz. Culturas inclusivas en educación media superior: construcción y validación de instrumentos Sinéctica 56 www.sinectica.iteso.mx 


\begin{tabular}{|c|c|c|}
\hline $\begin{array}{l}\text { “... patrones de significado que son transmitidos históricamente, y que } \\
\text { incluyen los valores, las normas, las creencias, los rituales, los mitos y } \\
\text { las ceremonias comprendidas, quizás en distinto grado, por los miem- } \\
\text { bros de la comunidad escolar (Stolp, 1994) y que los identifican como } \\
\text { integrantes de ella y, lógicamente, les permite comprender y comuni- } \\
\text { carse entre sí; siendo este sistema de significados lo que generalmente } \\
\text { estructura lo que la gente piensa y, por tal razón, la forma en que actúa" }\end{array}$ & Gálvez & 2006 (p. 93) \\
\hline $\begin{array}{c}\text { "La cultura escolar tiene una doble funcionalidad: establecer los límites } \\
\text { de la institución y proporcionar elementos de identidad y sentido de } \\
\text { pertenencia a los miembros que la componen" }\end{array}$ & $\begin{array}{l}\text { Molina y San- } \\
\text { doval }\end{array}$ & $\begin{array}{c}2006 \\
\text { (pp. 113-114) }\end{array}$ \\
\hline $\begin{array}{c}\text { "Procesos interactivos que van definiendo la realidad organizativa y } \\
\text { desde los cuales se generan creencias, códigos profesionales, roles y } \\
\text { patrones de acción" }\end{array}$ & Pérez y Quijano & 2010 (p. 66) \\
\hline $\begin{array}{c}\text { “... colección de tradiciones y rituales que se han ido construyendo a lo } \\
\text { largo del tiempo a medida que trabajan juntos maestros, estudiantes, } \\
\text { padres y administradores asumiendo crisis y logros" }\end{array}$ & $\begin{array}{c}\text { Hongboontri \& } \\
\text { Keawkhong }\end{array}$ & 2014 (p. 66) \\
\hline $\begin{array}{l}\text { “... hay acuerdo en que la cultura escolar, como la cultura en general, } \\
\text { tiene a la vez características estáticas y dinámicas. El carácter estático se } \\
\text { pone de manifiesto porque por un lado la cultura crea un carácter único } \\
\text { en el sistema social al promover un sentido de pertenencia y compro- } \\
\text { miso, y participa activamente en la socialización de nuevos miembros } \\
\text { introduciéndolos en una particular perspectiva de la realidad. Por otro, } \\
\text { está sujeta a cambios en tanto los miembros de la organización interac- } \\
\text { túan con nuevas ideas y enfoques, de ahí su carácter dinámico" }\end{array}$ & Elías & 2015 (p. 288) \\
\hline $\begin{array}{l}\text { "La cultura escolar suele tener en su haber normas y principios, supues- } \\
\text { tos básicos, ritos, valores y un lenguaje común, que no es solamente } \\
\text { propio de una cultura monolítica, sino que también se asocia a una serie } \\
\text { de estructuras internas que en conjunto construyen la identidad cultural } \\
\text { de una escuela. De igual forma, tales aspectos pueden relacionarse con } \\
\text { entidades externas que comparten ciertos elementos de la misma. Esta } \\
\text { cultura no se define conceptual ni pragmáticamente como algo alejado } \\
\text { de la historia, de la construcción social ni de su contexto; por el contra- } \\
\text { rio, es un concepto histórico, contingente y en constante construcción } \\
\text { dinámica, que evoluciona y se modifica a pesar de que en ocasiones pa- } \\
\text { rezca tener cierta estabilidad; transmitiéndose por medio de elementos } \\
\text { formales y definidos por la misma cultura dominante, la cual le otorga } \\
\text { sentido y significado (Bolívar, 1996)" }\end{array}$ & Guzmán & $\begin{array}{c}2015 \\
\text { (pp. 9-10) }\end{array}$ \\
\hline
\end{tabular}

Fuente: Elaboración propia a partir de los autores citados en la tabla.

Pese a la diversidad de definiciones y enfoques sobre el constructo cultura escolar, es posible distinguir dos grandes perspectivas. Por un lado, aquella que destaca la naturaleza estructurante de las culturas escolares que funge como reguladora de los colectivos y sus actividades (Guzmán, 2015; Pérez-Gómez, 2000; Molina y Sandoval, 2006). Por otro, está la que coloca en el centro el análisis de las interacciones entre los sujetos y los procesos identitarios que se desprenden de dichos intercambios y negociaciones de significados (Elías, 2015; Gálvez, 2006; Hongboontri \& Keawkhong, 2014; Huergo, 2001; Pérez y Quijano, 2010). En ambos casos se distinguen los valores, las normas, las tradiciones, los procesos de socialización y las metas comunes, que, si bien son transmitidos, poseen cierto dinamismo dependiendo del entorno y contexto donde se sitúen los centros escolares (Escolano, 2008; Frandsen, 2014; Guzmán, 2015).

Ante las múltiples aproximaciones, Lobato y Ortiz (2001) proponen una definición integradora del constructo cultura escolar y distinguen entre contenido y forma: "El contenido de la cultura escolar está definido por las actitudes, valores, creencias, hábitos, supuestos y formas de hacer las cosas, mientras que a la forma corresponden 
los modelos de relación y formas de asociación características de los participantes de esas culturas" (pp. 677-678).

Esta definición es la que sostenemos en este artículo, ya que nos permite articular tanto el cúmulo de saberes y prácticas como los sistemas de organización propios de los espacios escolares.

El constructo de culturas escolares ha tenido un peso importante en el enfoque de eficacia escolar. Cabe señalar que este enfoque surgió en franca contraposición al reproductivismo educativo, el cual señala que las escuelas perpetúan cierto statu quo del orden social y un sistema de dominación hacia los sectores populares. El famoso informe Coleman de la década de los sesenta es un claro ejemplo de esta mirada pesimista y desesperanzadora sobre el papel de la educación y las escuelas para atajar las desigualdades. Frente al reproductivismo, el enfoque de eficacia escolar se concentra en el análisis de los factores escolares que permiten elevar el "valor añadido" de la educación desde las prácticas escolares (López, 2005). Este se entiende como el valor añadido o agregado a los aportes al aprendizaje de los estudiantes a lo largo de sus trayectorias escolares.

Fernández (2004), en un análisis exhaustivo de la investigación sobre escuelas eficaces y sus implicaciones en políticas educativas, concluye que la contribución más relevante del estudio sobre las escuelas eficaces ha sido el cambio provocado en nuestras formas de comprender y gestionar las escuelas, ya que existe evidencia de que factores escolares hacen diferencia entre los sectores más pobres, en especial las prácticas pedagógicas de los maestros y el liderazgo de los directores como gestores de climas organizacionales colaborativos y orientados al logro educativo.

Alrededor del enfoque de eficacia escolar se han sumado movimientos similares; por ejemplo, para Murillo y Krichesky (2015), el enfoque de eficacia escolar se concentra en ciertos elementos escolares que repercuten en el aprendizaje y, de manera equivalente, el movimiento de mejora de la escuela destaca la importancia de promover y sostener cambios que ejerzan un impacto efectivo al interior de las aulas. En aras de conjuntar ambos enfoques, surge el de mejora de la eficacia escolar, en el cual no solo se interviene en aquellos elementos escolares que repercuten en el aprendizaje, sino en los procesos de cambio y en la apropiación de estos por las comunidades escolares.

Desde el enfoque de eficacia escolar, las culturas escolares son entendidas como "un sistema estructurador de la práctica que da lugar a que los agentes actúen de cierta forma, perciban, aprecien y evalúen las acciones de los demás miembros" (Aguilera, García, Huerta, Muñoz y Orozco, 2007, p. 253).

\section{Culturas inClusivas}

El índex de la inclusión elaborado por Booth y Aisncow y sus diferentes ediciones (2000, 2006 y 2015, entre otras) es reconocido como un parteaguas en la promoción de centros escolares inclusivos. La herramienta se sustenta en el trabajo colaborativo de las comunidades escolares dirigidas a mejorar los logros de todo el estudiantado. Para ello, se ofrece una serie de pautas que permiten tanto organizar un proceso de autoevaluación como guiar la construcción de centros escolares inclusivos a través del método de investigación-acción.

De la Cruz. Culturas inclusivas en educación media superior: construcción y validación de instrumentos Sinéctica 56 www.sinectica.iteso. $m x$ 
El índex integra tres dimensiones de análisis e intervención: culturas, políticas y prácticas de una educación inclusiva. Entendemos por culturas inclusivas aquellas que promueven comunidades seguras, acogedoras, colaboradoras, donde cada integrante es valorado y se fomentan altos niveles de logro, para lo cual se ponen en juego valores inclusivos que permean las actividades de todos los agentes que participan en las comunidades. Las políticas inclusivas aluden a que en todo proceso de innovación, e incluso de toma de decisiones, se fije como meta mejorar el aprendizaje y la participación de todo el estudiantado. Finalmente, las prácticas inclusivas se refieren a la concreción de la cultura y las políticas inclusivas en la participación, el reconocimiento y en el aprendizaje del estudiantado en todos los espacios escolares.

Si bien estas dimensiones están interconectadas y son fundamentales para la construcción de centros escolares inclusivos, en nuestro escrito nos centramos en la dimensión culturas inclusivas. En la tabla 2 incluimos definiciones de culturas inclusivas que han estado presentes en algunas de las ediciones del índex.

Tabla 2. Culturas inclusivas: definiciones en las versiones del índex de la inclusión

\begin{tabular}{|c|c|}
\hline Definiciones de culturas inclusivas & $\begin{array}{c}\text { Año de publicación } \\
\text { del índex }\end{array}$ \\
\hline $\begin{array}{l}\text { "Esta dimensión se relaciona con la creación de una comuni- } \\
\text { dad escolar segura, acogedora, colaboradora y estimulante, } \\
\text { en la que cada uno es valorado, lo cual es la base fundamental } \\
\text { primordial para que todo el alumnado tenga mayores niveles de } \\
\text { logro. Se refiere, asimismo, al desarrollo de valores inclusivos, } \\
\text { compartidos por todo el personal de la escuela, los estudiantes, } \\
\text { los miembros del Consejo Escolar y las familias, que se trans- } \\
\text { mitan a todos los nuevos miembros de la comunidad escolar" } \\
\text { (p. 18) }\end{array}$ & 2000 \\
\hline $\begin{array}{c}\text { "Esta dimensión tiene que ver con crear un entorno seguro, que } \\
\text { acepta, colabora, estimula, en el que todos son valiosos. Estos } \\
\text { valores inclusivos compartidos se desarrollan y transmiten } \\
\text { a los nuevos profesionales, a los niños, equipos directivos y } \\
\text { padres/cuidadores" (p. 16). }\end{array}$ & 2006 \\
\hline $\begin{array}{c}\text { "Esta dimensión está orientada hacia la reflexión sobre la } \\
\text { importancia de crear comunidades escolares seguras, acoge- } \\
\text { doras y colaboradoras, que resulten estimulantes y en las que } \\
\text { se acepta y se da la bienvenida a las distintas comunidades de } \\
\text { la localidad, lo que permite que, finalmente, cada uno se sienta } \\
\text { valorado. Ayuda a pensar en el hecho de que los valores inclusi- } \\
\text { vos deben ser compartidos por todas las personas que trabajan } \\
\text { en y con el centro escolar: el profesorado, los estudiantes, los } \\
\text { miembros del consejo escolar las familias, y sobre la forma en } \\
\text { que se transmiten estos valores a todos los nuevos miembros } \\
\text { de la comunidad escolar" (p. 50) }\end{array}$ & 2015 \\
\hline
\end{tabular}

Fuente: Elaboración propia con base en Booth y Ainscow $(2000,2015)$

y Booth, Ainscow y Kingston (2006).

En síntesis, una cultura inclusiva favorece el aprendizaje, construye comunidad y fortalece el sentido de pertenencia, la colaboración y el propio tejido social que trasciende el ámbito escolar. El cuidado, el respeto, la ayuda, las altas expectativas, la participación y la eliminación de cualquier tipo de exclusión son principios nodales de culturas inclusivas. 
Además, una cultura escolar que favorezca el trabajo colaborativo entre docentes y que reconozca a cada uno de sus integrantes será más proclive a la inclusión. Para Gutiérrez-Ortega, Martín-Cilleros y Jerano-Ríos (2018), centros educativos inclusivos "deberán promover culturas basadas en valores inclusivos, en el trabajo multidisciplinar, en una visión compartida y en la aceptación de la diversidad como elemento enriquecedor del centro" (p. 14). Sin embargo, el cambio de las culturas escolares hacia la inclusión no resulta una empresa sencilla; por ello, se requieren cambios paulatinos que trastoquen las prácticas cotidianas de las comunidades escolares.

Para Labajos, Gallego y Lago (2012), una cultura escolar inclusiva reconoce y valora la diversidad del alumnado. Estas autoras describen una serie de pautas en el marco de la inclusión de jóvenes migrantes que bien pueden aplicarse a los jóvenes en general: contar con un plan de acogida que integre tanto a los alumnos como a sus familias; facilitar que los alumnos conozcan las instalaciones, horarios, normas del centro y códigos que rigen los intercambios sociales; realizar actividades que promuevan el conocimiento entre compañeros; favorecer valores de empatía y solidaridad contrarios a conductas de discriminación, racismo y xenofobia; organizar al centro educativo y sus apoyos para que los estudiantes utilicen en la medida de lo posible todos los recursos ordinarios; dar seguimiento continuo de cada alumno. Como observamos, dichas pautas se sustentan en el reconocimiento, la participación, el trabajo colaborativo y la generación de culturas escolares que favorezcan el sentido de pertenencia y la creación de auténticas comunidades.

\section{ESCALAS Y HERRAMIENTAS PARA LA PROMOCIÓN DE CULTURAS INCLUSIVAS EN EDUCACIÓN MEDIA SUPERIOR}

Llevamos a cabo una búsqueda exhaustiva en las bases de datos ERIC, Dialnet, IRESIE y Redalyc de las palabras clave "culturas escolares AND escalas y culturas escolares inclusivas AND escalas” en artículos publicados en los últimos diez años (2010-2020); sin embargo, no identificamos escalas o herramientas para el nivel medio superior. Cabe señalar que, si bien la tercera edición del índex de la inclusión (Booth y Ainscow, 2015) integra una serie de escalas que exploran las dimensiones que conforman el índex (culturas inclusivas, políticas inclusivas y prácticas inclusivas), estas fueron diseñadas para la educación básica. Por ello, tanto la escala como la guía que a continuación describimos pretenden cubrir vacíos al respecto.

\section{MÉTOdo}

La escala "Culturas inclusivas en EMS" tiene como propósito ofrecer una herramienta válida y confiable para explorar las valoraciones y percepciones de estudiantes sobre la naturaleza inclusiva de las culturas escolares. Después de la validación de la escala, la adaptamos al formato de guía para orientar los esfuerzos de planteles de EMS en la promoción de culturas inclusivas. En esta guía se especifican una serie de preguntas para analizar, discutir y trazar perspectivas que redunden en el trabajo colaborativo de la comunidad en su conjunto. 
A continuación presentamos el proceso de construcción y validación de la escala como instrumento de diagnóstico. En un segundo momento, detallamos el procedimiento seguido para adaptar la escala al formato de guía como herramienta de apoyo para los centros escolares.

\section{Escala "Culturas inclusivas en EMS" como instrumento de diagnóstico}

Esta escala explora las valoraciones y percepciones de estudiantes sobre las culturas escolares y las caracteriza como inclusivas. Lo anterior significa que los resultados de la escala permiten tasar la naturaleza inclusiva de aquellas desde el punto de vista de los estudiantes. Vale la pena mencionar que la validación psicométrica de la escala se realizó exclusivamente con una muestra de estudiantes del subsistema técnico profesional, ya que, en su momento, las autoridades de este subsistema mostraron interés por su aplicación.

\section{Participantes}

Optamos por un muestreo estratificado por semestre que comprendió el total de la población en 2017 del subsistema técnico profesional de los 27 planteles del Colegio Nacional de Educación Profesional de la Ciudad de México. Para el cálculo de las muestras, consideramos un nivel de confianza del 95\% y un grado de error del 5\%. La distribución fue la siguiente:

$$
\begin{aligned}
& \text { - }{ }^{\circ} \text { o semestre: } N=16,201, n=375 \\
& \text {-4oㅡㄹ semestre: } N=11,585, n=372 \\
& \text {-6을 semestre: } N=9,467, n=369
\end{aligned}
$$

En números cerrados, participaron 400 estudiantes por semestre, lo que dio un total de 1,200. De este total, el 52\% fueron hombres y el 48\%, mujeres. El rango de edad fue de 15 a 47 años y la media de 17 años. El estado civil del 93\% fue soltero/a; el 5\% tenía hijos; el 47\% adeudaba materias; el 32\% había abandonado sus estudios de educación media durante un ciclo escolar y después regresado; el 31\% trabajaba además de estudiar; el 88\% vivía con sus padres; y el 36\% no contaba con una computadora o laptop con internet en casa para realizar trabajos escolares.

\section{Instrumento}

Para la elaboración del instrumento, diseñamos un plan de prueba sobre el constructo culturas inclusivas; para ello, analizamos literatura relacionada e, inicialmente, definimos cinco dimensiones (ver tabla 2), cada una con reactivos específicos. Para la definición de esas dimensiones, consideramos su pertinencia para el nivel medio superior y que aludieran tanto a actitudes, valores y creencias compartidas - contenido de la cultura- como a modelos de relación y modos de asociación y organización -forma de la cultura-, de acuerdo con la definición que Lobato y Ortiz (2001) ofrecen sobre culturas escolares. 
Esta propuesta hipotética sobre las dimensiones del constructo "cultura escolar inclusiva" se sometió a prueba empírica a través de la validación psicométrica, como lo describimos en los resultados; por ello, el lector identificará tanto la propuesta teórica de la escala (ver tabla 3) como su integración después de la validación psicométrica (ver tabla 4), lo cual permite evidenciar el proceso de construcción de la escala expuesta. Aclaramos que el trabajo de construcción de la escala estuvo a cargo de un equipo de investigación cuya línea de indagación son las culturas escolares en EMS e inclusión educativa.

Tabla 3. Dimensiones de las culturas inclusivas (propuesta teórica)

\begin{tabular}{|c|c|c|}
\hline Culturas escolares & $\begin{array}{l}\text { Dimensiones de las culturas } \\
\text { inclusivas }\end{array}$ & Reactivos \\
\hline \multirow{19}{*}{$\begin{array}{l}\text { A. Contenido de la } \\
\text { cultura }\end{array}$} & \multirow{8}{*}{$\begin{array}{l}\text { A1. Responsabilidad con el } \\
\text { aprendizaje }\end{array}$} & $\begin{array}{l}\text { Mi escuela ha fomentado que sea más responsable } \\
\text { con mis estudios }\end{array}$ \\
\hline & & $\begin{array}{l}\text { Los servicios que mi escuela me brinda me han ayu- } \\
\text { dado a permanecer en el plantel }\end{array}$ \\
\hline & & Mi escuela me brinda mejores opciones de futuro \\
\hline & & Mi escuela me ha permitido desarrollar mi potencial \\
\hline & & $\begin{array}{l}\text { Mi escuela proporciona ayuda a todos los estudiantes } \\
\text { para tener éxito con sus estudios }\end{array}$ \\
\hline & & $\begin{array}{l}\text { Considero que mi escuela me ha ayudado a mejorar } \\
\text { mi salud física y mental }\end{array}$ \\
\hline & & $\begin{array}{l}\text { Mi escuela promueve la discusión de asuntos sociales, } \\
\text { económicos o políticos de importancia para nuestra } \\
\text { sociedad }\end{array}$ \\
\hline & & $\begin{array}{c}\text { Mi escuela desarrolla actividades que contribuyen al } \\
\text { bien de la comunidad }\end{array}$ \\
\hline & \multirow{5}{*}{$\begin{array}{l}\text { A2. Espacios y clima escolar } \\
\text { afectivos }\end{array}$} & Soy importante en mi comunidad escolar \\
\hline & & Mi escuela cuenta con instalaciones en buen estado \\
\hline & & $\begin{array}{l}\text { Para las autoridades escolares es importante la opi- } \\
\text { nión de los estudiantes }\end{array}$ \\
\hline & & $\begin{array}{l}\text { Las autoridades de mi escuela mantienen comunica- } \\
\text { ción con los estudiantes }\end{array}$ \\
\hline & & Me gusta estar dentro de mi escuela \\
\hline & \multirow{6}{*}{$\begin{array}{l}\text { A3. Sentido de pertenencia y } \\
\text { confianza en el centro }\end{array}$} & $\begin{array}{l}\text { Me siento orgulloso/a de que la sociedad me reco- } \\
\text { nozca como miembro de mi institución educativa }\end{array}$ \\
\hline & & $\begin{array}{l}\text { Me identifico con la comunidad estudiantil de mi } \\
\text { escuela }\end{array}$ \\
\hline & & $\begin{array}{c}\text { Si comenzara otra vez mis estudios, elegiría el plantel } \\
\text { donde estoy estudiando }\end{array}$ \\
\hline & & $\begin{array}{c}\text { En caso de algún problema dentro de la escuela, sé } \\
\text { con quién acudir }\end{array}$ \\
\hline & & $\begin{array}{l}\text { Me gusta participar en fiestas y festivales dentro de } \\
\text { mi escuela (ej. día de muertos, posadas, conmemora- } \\
\text { ción de fechas cívicas, etc.) }\end{array}$ \\
\hline & & $\begin{array}{l}\text { Participo junto con otros compañeros/as para resol- } \\
\text { ver problemáticas que afectan a mi escuela }\end{array}$ \\
\hline
\end{tabular}

De la Cruz. Culturas inclusivas en educación media superior: construcción y validación de instrumentos Sinéctica 56 www.sinectica.iteso.mx 


\begin{tabular}{|c|c|c|}
\hline \multirow{12}{*}{$\begin{array}{l}\text { B. Forma de la } \\
\text { cultura }\end{array}$} & \multirow{7}{*}{$\begin{array}{l}\text { B1. Colaboración entre pares y } \\
\text { aprendizaje }\end{array}$} & $\begin{array}{c}\text { Tengo amigos/as en mi escuela que me ayudan a } \\
\text { estudiar }\end{array}$ \\
\hline & & $\begin{array}{c}\text { Me reúno con otros compañeros/as para estudiar } \\
\text { fuera del salón de clases }\end{array}$ \\
\hline & & Cuando trabajo en equipo mi opinión es importante \\
\hline & & $\begin{array}{l}\text { Fuera del salón dialogo con otros compañeros/as } \\
\text { sobre los temas revisados en clase }\end{array}$ \\
\hline & & $\begin{array}{c}\text { Para preparar un examen estudio con otros compa- } \\
\text { ñeros/as }\end{array}$ \\
\hline & & Explico lo revisado en clase a otros compañeros/as \\
\hline & & $\begin{array}{l}\text { Busco ayuda de mis compañero/as cuando no com- } \\
\text { prendo algo de las clases }\end{array}$ \\
\hline & \multirow{5}{*}{ B2. Seguridad escolar } & La zona donde se ubica mi escuela es segura \\
\hline & & Me siento seguro/a dentro de mi escuela \\
\hline & & En mi escuela me siento protegido/a \\
\hline & & La zona que rodea mi escuela es segura \\
\hline & & Confío en el personal de seguridad de mi escuela \\
\hline
\end{tabular}

Como apreciamos en la tabla 3, las dimensiones que teóricamente conjuntaron el contenido de las culturas inclusivas fueron: A1. Responsabilidad con el aprendizaje; A2. Espacios y clima escolar afectivos; y A3. Sentido de pertenencia y confianza en el centro. La primera se refiere a los valores que fomenta el centro escolar para que el estudiantado se asuma como sujeto activo en su propio aprendizaje, y tenga en cuenta que una cultura escolar inclusiva orienta sus esfuerzos para que todos aprendan. La segunda se relaciona con la generación de espacios y ambientes escolares donde los estudiantes se sientan estimados y valorados. La tercera alude al fomento del sentido de pertenencia y confianza en el centro; en esta dimensión se espera que los centros escolares promuevan vínculos con los estudiantes que favorezcan que estos se sientan identificados.

Por su parte, las dimensiones relacionadas con la forma de la cultura escolar fueron: B1. Colaboración entre pares y aprendizaje y B2. Seguridad escolar. Durante la revisión de la literatura sobre culturas inclusivas fue recurrente el hincapié en la colaboración como un componente distintivo de este tipo de culturas. Por ello, en la escala se incorporó una dimensión que, de manera específica, explorara el fomento de la colaboración entre pares y su aporte al aprendizaje. Finalmente, la dimensión seguridad escolar concierne a la generación de ambientes escolares seguros y protectores.

Después de la elaboración del plan de prueba expuesto en la tabla 3, verificamos la claridad y pertinencia de cada reactivo; para ello, consultamos a 25 estudiantes de EMS. El primer criterio para su selección fue que estuvieran inscritos en una institución de EMS y, posteriormente, que pertenecieran a una opción pública del nivel en cuestión; en total, 12 jóvenes se encontraban estudiando el bachillerato general, 8, el profesional técnico y 5, el bachillerato tecnológico. Optamos por una escala de respuesta tipo Likert y valoramos el grado de acuerdo con cada reactivo. Las opciones de respuesta fueron: 1 . Totalmente en desacuerdo; 2 . En desacuerdo; 3 . Ni de acuerdo ni en desacuerdo; 4. De acuerdo y 5. Totalmente de acuerdo. El instrumento quedó integrado por dos secciones: datos sociodemográficos y escala del constructo de interés. 
Procedimiento

Para la aplicación del instrumento, contamos con el apoyo de orientadores y autoridades escolares de los 27 planteles del Colegio Nacional de Educación Profesional de la Ciudad de México. Llevamos a cabo una breve capacitación virtual para estandarizar el proceso de aplicación y enviar los instrumentos a cada plantel. Dado que la escala fue de autoaplicación, quienes fungieron como aplicadores solo resolvieron dudas sobre su llenado. Cabe señalar que, antes de la aplicación, preguntamos a los estudiantes seleccionados de manera aleatoria si estaban dispuestos a participar y respetamos la decisión de aquellos cuya respuesta fue negativa. En cada plantel se destinó un espacio para la aplicación y, en promedio, durante una semana recabamos la información. Concluida la aplicación, los instrumentos fueron regresados a una oficina central. Participaron 27 aplicadores (orientadores o responsables académicos), quienes tuvieron el apoyo de autoridades escolares. En total se aplicaron 1,400 instrumentos.

En cuanto al procedimiento para la validación psicométrica de la escala, realizamos lo siguiente:

-Elaboración de una base de datos con el programa SPSS v.22®.

-Captura de la aplicación.

-Análisis de frecuencias por cada reactivo.

-Análisis de discriminación por medio del método de grupos contrastados ( $\mathrm{t}$ de Student).

- Correlaciones de cada reactivo con el puntaje total.

-Análisis factoriales de componentes principales con rotación ortogonal (varimax).

-Cálculo del coeficiente de confiabilidad a través del método alfa de Cronbach (por cada componente y de la escala en su conjunto).

-Validez de constructo (correlación dominio total y correlación entre índices).

Guía "Promoción de culturas inclusivas en educación media superior: construcción de proyectos comunes"

Considerando los resultados obtenidos en la validación psicométrica de la escala "Culturas inclusivas en EMS" y teniendo como referente las diferentes ediciones del índex de la inclusión elaborado por Booth y Ainscow, formulamos una propuesta de guía para los planteles cuyo propósito fue ofrecer una serie de pautas de análisis y orientaciones a nivel escolar.

\section{Participantes}

La guía se sometió a revisión de 14 orientadores y 6 directivos de distintos planteles de EMS correspondientes al bachillerato general, tecnológico y profesional técnico. La edad promedio de los participantes fue de 53 años: 12 mujeres y 8 hombres. 
Todos con estudios de educación superior y, en promedio, 16 años de antigüedad laboral en el nivel medio superior.

Instrumento

La guía integra los factores derivados de la validación psicométrica de la escala "Culturas inclusivas en EMS". Cabe señalar que en la guía los factores se denominaron dimensiones, ya que fue una palabra más accesible y significativa para los participantes. Para su revisión y validación, brindamos a los participantes una descripción amplia de cada dimensión. A diferencia de la escala, en la guía los ítems se plantearon como interrogantes. Por cada pregunta, valoramos su claridad y pertinencia con la dimensión de referencia y, en su caso, sugerimos ajustes.

Procedimiento

Con cada participante consideramos los siguientes pasos:

-Presentación de la guía.

-Exposición de cada uno de los factores derivados de la validación psicométrica de la escala "Culturas inclusivas en EMS". En la guía estos factores se nombraron dimensiones, ya que resultaban más pertinenten dado su formato y sentido.

-Cada participante leía en conjunto cada dimensión y las preguntas correspondientes.

-Después de la lectura, los participantes señalaron su grado de acuerdo con la claridad y pertinencia de cada pregunta y ofrecieron sugerencias al respecto. En este sentido, lo que priorizamos fue establecer consensos con los participantes, más que obtener el porcentaje de acuerdo entre jueces.

-Con el total de las valoraciones, construimos una segunda propuesta que integra lo expresado por los participantes y que exponemos en la siguiente sección.

\section{RESULTADOS}

\section{Escala "Culturas inclusivas en EMS"}

Antes de la validación del instrumento a través de análisis factoriales, probamos su pertinencia mediante la prueba de adecuación muestral de Kaiser-Meyer-Olkin y la prueba de esfericidad de Bartlett. De la primera, destacamos que obtuvimos un valor de .95 (es aceptable con un valor $>.50$ ), mientras que en la segunda logramos una p. 00 (es aceptable una $p<.05$ ). Dado que en ambas pruebas los resultados fueron positivos, procedimos a realizar un análisis factorial para identificar la estructura latente del instrumento y someter a prueba empírica la propuesta que, teóricamente, se construyó sobre el constructo cultura escolar inclusiva (expuesto en la tabla 3). 
En cuanto al método factorial, optamos por componentes principales con rotación varimax y elegimos solo los ítems cuya carga factorial fuera igual o mayor de.40. Fueron eliminados reactivos que cargaran en más de un factor con .40. La escala en su conjunto obtuvo una alta confiabilidad $(\alpha=.92)$. Los resultados se observan en la tabla 4.

Tabla 4. Análisis de componentes principales con rotación varimax y coeficiente alfa para la escala "Culturas inclusivas en EMS"

\begin{tabular}{|c|c|}
\hline Factores y reactivos & Carga factorial \\
\hline \multicolumn{2}{|c|}{ Factor 1. Responsabilidad con el aprendizaje y sentido de pertenencia $(\alpha=.86)$} \\
\hline Mi escuela ha fomentado que sea más responsable con mis estudios & .72 \\
\hline $\begin{array}{l}\text { Los servicios que mi escuela me brinda me han ayudado a } \\
\text { permanecer en el plantel }\end{array}$ & .70 \\
\hline $\begin{array}{l}\text { Me siento orgulloso/a de que la sociedad me reconozca como } \\
\text { miembro de mi institución educativa }\end{array}$ & .68 \\
\hline Mi escuela me brinda mejores opciones de futuro & .66 \\
\hline Mi escuela me ha permitido desarrollar mi potencial & .66 \\
\hline $\begin{array}{l}\text { Mi escuela proporciona ayuda a todos los estudiantes } \\
\text { para tener éxito con sus estudios }\end{array}$ & .61 \\
\hline Soy importante en mi comunidad escolar & .57 \\
\hline Para las autoridades escolares es importante la opinión de los estudiantes & .56 \\
\hline Me identifico con la comunidad estudiantil de mi escuela & .55 \\
\hline Mi escuela cuenta con instalaciones en buen estado & .53 \\
\hline Considero que mi escuela me ha ayudado a mejorar mi salud física y mental & .53 \\
\hline Tengo amigos/as en mi escuela que me ayudan a estudiar & .51 \\
\hline Si comenzara otra vez mis estudios, elegiría el plantel donde estoy estudiando & .45 \\
\hline \multicolumn{2}{|l|}{ Factor 2. Ambiente escolar afectivo $(\alpha=.76)$} \\
\hline En mi escuela me siento protegido/a & .64 \\
\hline En caso de algún problema dentro de la escuela, sé con quién acudir & .64 \\
\hline Me gusta estar dentro de mi escuela & .63 \\
\hline Me siento seguro/a dentro de mi escuela & .60 \\
\hline Cuando trabajo en equipo mi opinión es importante & .55 \\
\hline \multicolumn{2}{|l|}{ Factor 3. Construcción social del conocimiento ( $\alpha=.73)$} \\
\hline $\begin{array}{l}\text { Fuera del salón dialogo con otros compañeros/as } \\
\text { sobre los temas revisados en clase }\end{array}$ & .72 \\
\hline Explico lo revisado en clase a otros compañeros/as & .72 \\
\hline Para preparar un examen, estudio con otros compañeros/as & .65 \\
\hline Me reúno con otros compañeros/as para estudiar fuera del salón de clases & .55 \\
\hline Busco ayuda de mis compañero/as cuando no comprendo algo de las clases & .46 \\
\hline \multicolumn{2}{|l|}{ Factor 4. Desarrollo de ciudadanía y participación social ( $\alpha=.76)$} \\
\hline $\begin{array}{l}\text { Mi escuela promueve la discusión de asuntos sociales, económicos o políticos de } \\
\text { importancia para nuestra sociedad }\end{array}$ & .66 \\
\hline $\begin{array}{l}\text { Me gusta participar en fiestas y festivales dentro de mi escuela } \\
\text { (ej. día de muertos, posadas, conmemoración de fechas cívicas, etc.) }\end{array}$ & .64 \\
\hline Mi escuela desarrolla actividades que contribuyen al bien de la comunidad & .59 \\
\hline $\begin{array}{c}\text { Participo junto con otros compañeros/as para resolver } \\
\text { problemáticas que afectan a mi escuela }\end{array}$ & .54 \\
\hline Las autoridades de mi escuela mantienen comunicación con los estudiantes & .43 \\
\hline \multicolumn{2}{|l|}{ Factor 5. Seguridad escolar y sus entornos $(\alpha=.63)$} \\
\hline La zona que rodea mi escuela es segura & .67 \\
\hline La zona donde se ubica mi escuela es segura & .62 \\
\hline Confío en el personal de seguridad de mi escuela & .54 \\
\hline
\end{tabular}

Cada uno de los cinco factores obtuvieron valores Eigen superiores a $1.0 \mathrm{y}$, en su conjunto, explican el $50.95 \%$ de la varianza, como se aprecia en la tabla 5 . 
Tabla 5. Valores propios, porcentaje de varianza y porcentaje acumulado por factores de la escala "Culturas inclusivas en EMS"

\begin{tabular}{|c|c|c|c|}
\hline Factor & Valor propio & $\begin{array}{c}\text { Porcentaje de } \\
\text { varianza }\end{array}$ & $\begin{array}{c}\text { Porcentaje } \\
\text { acumulado }\end{array}$ \\
\hline 1 & 10.21 & 31.93 & 31.93 \\
\hline 2 & 2.27 & 6.96 & 38.89 \\
\hline 3 & 1.40 & 4.39 & 43.29 \\
\hline 4 & 1.35 & 4.22 & 47.51 \\
\hline 5 & 1.10 & 3.43 & 50.95 \\
\hline
\end{tabular}

Finalmente, la validez de constructo a través de las correlaciones dominio (factores e indicadores) con el total oscilaron por arriba de .50 con un nivel de significancia de .01. Lo anterior permite afirmar que cada dominio mantiene una buena correlación con el conjunto de los dominios.

La tabla 4 revela que la validación psicométrica de la escala reconfiguró la construcción teórica expuesta en la tabla 3, y la hizo más robusta y pertinente para el nivel de EMS. Con base en los resultados de la validación psicométrica, en la tabla 6 definimos los factores que integran la escala apelando al contenido de los reactivos.

Tabla 6. Factores de la escala "Culturas inclusivas en EMS"

\begin{tabular}{|c|c|}
\hline Factores & Definición \\
\hline $\begin{array}{l}\text { Factor } 1 \text {. Responsabilidad con el } \\
\text { aprendizaje y sentido de pertenencia }\end{array}$ & $\begin{array}{c}\text { Condiciones escolares que favorecen que los } \\
\text { estudiantes se involucren con sus estudios } \\
\text { y generen sentido de pertenencia con el } \\
\text { plantel }\end{array}$ \\
\hline Factor 2. Ambiente escolar afectivo & $\begin{array}{l}\text { Construcción de ambientes escolares que } \\
\text { brindan cuidado, protección y reconocimien- } \\
\text { to a los estudiantes }\end{array}$ \\
\hline $\begin{array}{l}\text { Factor 3. Construcción social del } \\
\text { conocimiento }\end{array}$ & $\begin{array}{l}\text { Intercambios y colaboración entre pares que } \\
\text { contribuyen al aprendizaje }\end{array}$ \\
\hline $\begin{array}{l}\text { Factor 4. Desarrollo de ciudadanía y } \\
\text { participación social }\end{array}$ & $\begin{array}{l}\text { Promoción del ejercicio de derechos con una } \\
\text { clara intención de implicar a los jóvenes en } \\
\text { actividades que promueven su participación } \\
\text { en asuntos que benefician a las comunidades }\end{array}$ \\
\hline $\begin{array}{l}\text { Factor 5. Seguridad escolar y sus } \\
\text { entornos }\end{array}$ & $\begin{array}{l}\text { Contextos internos y externos a los centros } \\
\text { escolares que ofrecen a los estudiantes segu- } \\
\text { ridad y confianza para desenvolverse }\end{array}$ \\
\hline
\end{tabular}

Guía "Promoción de culturas inclusivas en educación media superior: construcción de proyectos comunes"

A continuación exponemos, de manera resumida, esta guía. Es importante señalar que esta es susceptible de adaptarse a las necesidades de cada plantel y requiere el trabajo colaborativo de las comunidades educativas. Buscamos que cada dimensión fomente el análisis y la reflexión sobre las culturas escolares, de ahí el interés por explorar las acciones, estrategias y programas encabezados por los planteles. Además, en cada dimensión se espera que se incorporen nuevas interrogantes derivadas del trabajo conjunto de los equipos de trabajo. 
Tabla 7. Guía "Promoción de culturas inclusivas: construcción de proyectos comunes"

\begin{tabular}{|c|c|}
\hline Propósito & $\begin{array}{l}\text { Con esta guía se pretende ofrecer una serie de interrogantes para analizar } \\
\text { la naturaleza inclusiva de las culturas escolares de planteles de educación } \\
\text { media superior }\end{array}$ \\
\hline \multirow{4}{*}{$\begin{array}{l}\text { Encuadre general sobre el } \\
\text { uso de la guía }\end{array}$} & $\begin{array}{l}\text { Se sugiere que antes de usar esta guía se aplique la escala “Culturas inclusi- } \\
\text { vas en EMS” y se analicen los resultados. En seguida, se propone la confor- } \\
\text { mación de un equipo coordinador integrado por docentes, orientadores, } \\
\text { autoridades, estudiantes y colegas externos al plantel, quienes tendrán la } \\
\text { función de ofrecer puntos de vista alternos. Las actividades que debe reali- } \\
\text { zar dicho equipo se conjuntarán en tres fases: }\end{array}$ \\
\hline & $\begin{array}{l}\text { Primera fase. Se espera que el equipo coordinador discuta la guía y recabe } \\
\text { evidencia sobre cada una de las preguntas. En esta etapa es deseable que } \\
\text { los participantes sumen nuevas interrogantes que permitan enriquecer el } \\
\text { cuestionamiento de cada dimensión }\end{array}$ \\
\hline & $\begin{array}{c}\text { Segunda fase. El equipo coordinador, a partir de los resultados de la primera } \\
\text { fase, ponderará cada una de las dimensiones para su intervención e invitará } \\
\text { a integrantes de la comunidad educativa con el propósito de planear y } \\
\text { desarrollar proyectos que propicien la construcción de culturas inclusivas. } \\
\text { Se espera que las comunidades educativas, en su conjunto, conozcan los } \\
\text { proyectos y se involucren en su desarrollo }\end{array}$ \\
\hline & $\begin{array}{c}\text { Tercera fase. Puesta en marcha de proyectos. En esta fase es muy impor- } \\
\text { tante comunicar los avances y resultados obtenidos. De manera paralela, es } \\
\text { deseable que, para sostener los cambios en las culturas escolares a lo largo } \\
\text { del tiempo, se incorporen de modo gradual como parte de las dinámicas } \\
\text { institucionales }\end{array}$ \\
\hline \multirow{13}{*}{$\begin{array}{l}\text { Dimensión } 1 \\
\text { Responsabilidad con el apren- } \\
\text { dizaje y sentido de pertenen- } \\
\text { cia: condiciones escolares } \\
\text { que favorecen que alumnos y } \\
\text { alumnas se involucren con sus } \\
\text { estudios y generen sentido de } \\
\text { pertenencia con el plantel }\end{array}$} & Preguntas clave \\
\hline & $\begin{array}{c}\text { ¿A través de qué mecanismos el plantel ha fomentado que los estudiantes } \\
\text { sean más responsables con sus estudios? }\end{array}$ \\
\hline & $\begin{array}{c}\text { ¿Qué servicios ofrece el plantel para favorecer la permanencia de los } \\
\text { estudiantes? }\end{array}$ \\
\hline & $\begin{array}{c}\text { ¿Cómo se promueve que los estudiantes se sientan orgullosos de pertenecer } \\
\text { al plantel? }\end{array}$ \\
\hline & $\begin{array}{c}\text { ¿Cómo contribuye el plantel a construir mejores opciones de futuro hacia los } \\
\text { estudiantes? }\end{array}$ \\
\hline & $\begin{array}{c}\text { ¿Qué acciones se realizan al interior del plantel para desarrollar el potencial } \\
\text { de todos los estudiantes? }\end{array}$ \\
\hline & $\begin{array}{l}\text { ¿Qué ayudas proporciona el plantel para que todos los estudiantes tengan } \\
\text { éxito con sus estudios? }\end{array}$ \\
\hline & $\begin{array}{l}\text { ¿Cómo se comunica a los estudiantes su importancia dentro de la } \\
\text { comunidad escolar? }\end{array}$ \\
\hline & $\begin{array}{c}\text { ¿Qué mecanismos utilizan las autoridades para conocer la opinión de los } \\
\text { estudiantes y para qué asuntos se prioriza su opinión? }\end{array}$ \\
\hline & $\begin{array}{c}\text { ¿Cómo se favorece que los estudiantes se identifiquen con la comunidad } \\
\text { escolar? }\end{array}$ \\
\hline & $\begin{array}{c}\text { ¿Cómo se garantiza que las instalaciones de la escuela se encuentren en } \\
\text { buen estado y sean aprovechadas por todos? }\end{array}$ \\
\hline & $\begin{array}{c}\text { ¿En qué medida la escuela contribuye a mejorar la salud física y mental de } \\
\text { todos los estudiantes? }\end{array}$ \\
\hline & Otras preguntas.... \\
\hline
\end{tabular}




\begin{tabular}{|c|c|}
\hline \multirow{6}{*}{$\begin{array}{c}\text { Dimensión } 2 \\
\text { Ambiente escolar afectivo: } \\
\text { construcción de ambientes es- } \\
\text { colares que brindan cuidado, } \\
\text { protección y reconocimiento a } \\
\text { los estudiantes }\end{array}$} & $\begin{array}{c}\text { Preguntas clave } \\
\text { ¿Cómo fomenta el plantel que los estudiantes se sientan protegidos al inte- } \\
\text { rior de él? }\end{array}$ \\
\hline & $\begin{array}{l}\text { ¿El plantel ofrece apoyos a los estudiantes en caso de algún problema que } \\
\text { afecte su rendimiento? ¿Cómo se socializan y difunden dichos apoyos? }\end{array}$ \\
\hline & $\begin{array}{c}\text { ¿Cómo promueve el plantel que los estudiantes disfruten su estancia al } \\
\text { interior de él? }\end{array}$ \\
\hline & $\begin{array}{c}\text { ¿Qué acciones ha tomado el plantel para que los estudiantes se sientan } \\
\text { seguros al interior de él? }\end{array}$ \\
\hline & ¿Cómo se fomenta la expresión y el respeto a las distintas opiniones? \\
\hline & Otras preguntas... \\
\hline \multirow{6}{*}{$\begin{array}{c}\text { Dimensión } 3 \\
\text { Construcción social del } \\
\text { conocimiento: intercambios y } \\
\text { colaboración entre pares que } \\
\text { contribuyen al aprendizaje }\end{array}$} & Preguntas clave \\
\hline & $\begin{array}{c}\text { ¿Qué acciones o estrategias promueve el plantel fuera del aula para } \\
\text { favorecer el diálogo entre los estudiantes sobre los temas revisados en } \\
\text { clase? }\end{array}$ \\
\hline & ¿Cómo motiva el plantel la colaboración entre estudiantes? \\
\hline & $\begin{array}{c}\text { ¿Al interior del plantel hay espacios físicos donde los estudiantes se reúnen } \\
\text { para estudiar? ¿Qué hace el plantel para apoyar el aprendizaje en dichos } \\
\text { espacios? }\end{array}$ \\
\hline & $\begin{array}{c}\text { ¿El plantel cuenta con programas de tutoría entre pares? ¿Cómo se organiza } \\
\text { dicho programa? }\end{array}$ \\
\hline & Otras preguntas.... \\
\hline \multirow{7}{*}{$\begin{array}{c}\text { Dimensión } 4 \\
\text { Desarrollo de ciudadanía y } \\
\text { participación social: promo- } \\
\text { ción del ejercicio de derechos } \\
\text { con una clara intención de } \\
\text { implicar a los jóvenes en } \\
\text { actividades que promueven su } \\
\text { participación en asuntos que } \\
\text { benefician a las comunidades }\end{array}$} & Preguntas clave \\
\hline & $\begin{array}{l}\text { ¿Qué tipo de actividades o proyectos promueve el plantel para discutir } \\
\text { como colectivo asuntos sociales, económicos o políticos de importancia para } \\
\text { nuestra sociedad? ¿Qué papel asumen los estudiantes en dichas actividades } \\
\text { o proyectos? ¿Cómo se promueve la participación de los estudiantes? }\end{array}$ \\
\hline & $\begin{array}{l}\text { ¿Cómo se favorece la colaboración entre estudiantes en la organización de } \\
\text { fiestas y festivales dentro del plantel (ej. día de muertos, posadas, conme- } \\
\text { moración de fechas cívicas, etc.)? ¿Qué tipo de valores se priorizan en la } \\
\text { organización de dichas actividades? }\end{array}$ \\
\hline & $\begin{array}{c}\text { ¿Qué tipo de actividades o proyectos fomenta el plantel para involucrar a } \\
\text { los estudiantes en acciones que contribuyan al bien de sus comunidades? } \\
\text { ¿Cómo se vinculan los aprendizajes escolares con dichas actividades o } \\
\text { proyectos? }\end{array}$ \\
\hline & $\begin{array}{c}\text { ¿Cómo se fomenta y alienta la participación de los estudiantes para resolver } \\
\text { problemáticas que afectan al plantel? }\end{array}$ \\
\hline & $\begin{array}{l}\text { ¿Qué tipo de canales ofrecen las autoridades escolares para mantener comu- } \\
\text { nicación con los estudiantes? }\end{array}$ \\
\hline & Otras preguntas... \\
\hline \multirow{5}{*}{$\begin{array}{c}\text { Dimensión } 5 \\
\text { Seguridad escolar y sus entor- } \\
\text { nos: contextos internos y ex- } \\
\text { ternos a los centros escolares } \\
\text { que ofrecen a los estudiantes } \\
\text { seguridad y confianza para } \\
\text { desenvolverse }\end{array}$} & Preguntas clave \\
\hline & $\begin{array}{c}\text { ¿Qué acciones, estrategias o programas instrumenta el plantel en } \\
\text { colaboración con otras instancias externas para garantizar la seguridad de } \\
\text { los estudiantes alrededor del plantel? }\end{array}$ \\
\hline & $\begin{array}{c}\text { ¿Qué acciones, estrategias o programas instrumenta el plantel en } \\
\text { colaboración con otras instancias externas para garantizar la seguridad de } \\
\text { los estudiantes en la zona donde se ubica el plantel? }\end{array}$ \\
\hline & $\begin{array}{c}\text { ¿Cómo se favorece que los estudiantes confíen en el personal de seguridad } \\
\text { del plantel? }\end{array}$ \\
\hline & Otras preguntas... \\
\hline
\end{tabular}




\section{DiSCUSIÓN Y CONCLUSIONES}

En este artículo hemos expuesto dos procesos complementarios en pro de construir y ofrecer instrumentos desde el enfoque de eficacia escolar que fortalezcan las culturas inclusivas en EMS. Situar los dos instrumentos en la EMS no es menor, ya que este nivel en nuestro país, pese a su obligatoriedad y el aumento en la cobertura, sigue siendo el cuello de botella del sistema educativo si consideramos indicadores como la reprobación, la repetición y el abandono escolar.

Sobre la validación psicométrica de la escala "Culturas inclusivas en EMS", destaca su alta confiabilidad $(\alpha=.92)$ y la integración de cinco factores que, en conjunto, explican casi un 51\% de la varianza. Si bien la validación reestructuró la propuesta teórica, los factores resultantes son más amplios y pertinentes para el nivel medio superior. El factor 1 (responsabilidad con el aprendizaje y sentido de pertenencia) se relaciona con las condiciones escolares que favorecen que los estudiantes se involucren con sus estudios y generen sentido de pertenencia, lo cual es vital a la luz de diversos estudios tanto nacionales (SEP, 2012) como internacionales (López, Opertti y Vargas, 2017), que han evidenciado que la desafiliación y el abandono escolar son producto, en parte, de las oportunidades que ofrecen los centros escolares para cambiar los entornos donde se desarrollan los jóvenes y se asuma a la educación como una verdadera oportunidad para trazar alternativas de vida.

El factor 2 (ambiente escolar afectivo) evoca la construcción de ambientes escolares que brindan cuidado, protección y reconocimiento a los estudiantes. Este componente en las culturas inclusivas adquiere relevancia si consideramos que los jóvenes de edades comprendidas entre los 15 y 18 años (+-1) experimentan cambios importantes tanto en términos de maduración como en procesos de autonomía y toma de decisiones que requieren ser alentados y orientados en pro de fomentar mayor seguridad y confianza en sí mismos, más cuando los hogares, e incluso los entornos donde se desarrollan, se encuentran colapsados por la violencia. Aquí, las culturas inclusivas ofrecen nichos de desarrollo y reconocimiento a la diversidad.

El factor 3 (construcción social del conocimiento) integra los intercambios y la colaboración entre pares que contribuye al aprendizaje. En el planteamiento teórico, algunos de los ítems que integran este factor formaban parte de la dimensión B1 (colaboración entre pares y aprendizaje); sin embargo, una nueva lectura a partir de la validación psicométrica nos permitió identificar que esa colaboración alude a la construcción conjunta del conocimiento; por ello, modificamos su nombre. En dicha construcción, la alteridad es vital, ya que, como menciona Muñoz (2009), provoca apertura hacia el otro y, con ello, reconocimiento a la diversidad como parte nodal de la inclusión.

El factor 4 (desarrollo de ciudadanía y participación social) se refiere al fomento del ejercicio de derechos y la participación de los jóvenes en asuntos que beneficien a las comunidades internas y externas a los centros escolares. Este factor se omitió en la propuesta teórica; no obstante, la validación psicométrica integró reactivos que ponen al centro las acciones escolares que permiten que los estudiantes discutan, participen e intervengan en asuntos que contribuyen al bien común. Una cultura inclusiva en educación media es el espacio propicio para que los estudiantes tomen decisiones y participen en ambientes democráticos que sean la semilla para asumir 
compromisos como ciudadanos, y con ello abonen a la integración de las formas de intervención social de los jóvenes a las culturas escolares (Valdez, Román, Cubillas y Moreno, 2008).

Por último, el factor 5 (seguridad escolar y sus entornos) se refiere al grado de confianza para desenvolverse sin temor a sufrir algún tipo de violencia. Este factor, en el caso de la EMS, es imprescindible si consideramos que, como sociedad, hemos sido testigos de lamentables hechos que viven estudiantes al interior y exterior de los planteles y que, incluso, ha dado lugar a acciones coordinadas con autoridades estatales para crear senderos seguros donde puedan transitar los jóvenes a su llegada y salida de los centros escolares. Una cultura escolar inclusiva en este tipo de condiciones tendrá que velar por la seguridad y el bienestar de cada uno de sus integrantes.

Por su parte, a través de la guía "Promoción de culturas inclusivas en EMS: construcción de proyectos comunes”, esperamos, ante todo, promover el trabajo colaborativo al interior de los planteles, así como la reflexión de asuntos torales propios de cada centro escolar. Desde la colaboración y construcción de comunidad, pretendemos aportar a la generación de culturas inclusivas. Las limitaciones de la escala se concentran en su capacidad para favorecer el trabajo colaborativo dentro de los planteles y su flexibilidad para adaptarse a los múltiples contextos.

Si bien la escala fue validada con una muestra de estudiantes de EMS del subsistema técnico profesional, buscamos que los reactivos aludieran al constructo culturas inclusivas, pero no a la opción educativa; sin embargo, habrá que probar su validez y pertinencia en otros subsistemas del nivel en cuestión. Si bien la guía fue expuesta y enriquecida mediante el diálogo con orientadores y autoridades educativas, queda pendiente su puesta en marcha y los posibles ajustes de acuerdo con los diferentes contextos y necesidades de los centros escolares. Con ambos instrumentos, nuestra intención es poner en el centro la construcción de condiciones escolares que favorezcan el aprendizaje de todos los estudiantes, así como el desarrollo pleno y digno de las comunidades educativas.

Finalmente, algunas áreas de intervención que quedan pendientes por explorar como parte de las culturas inclusivas en EMS son: la participación y formación de las familias; la creación de ambientes de colaboración entre el personal administrativo y académico; la vinculación plena y consistente con las comunidades externas a los centros escolares en aras de contribuir al bien común; y el avance en la construcción de ambientes seguros y libres de violencia al exterior e interior de los planteles, entre otros. 


\section{REFERENCIAS BIBLIOGRÁFICAS}

Aguilera, A., García, A., Huerta, E., Muñoz, G. y Orozco, A. (2007). Los procesos escolares en veinte escuelas secundarias mexicanas desde la perspectiva de la eficacia escolar: el clima y la cultura escolar. Revista Electrónica Iberoamericana sobre Calidad, Eficacia y Cambio en Educación, vol. 5, núm. 5e, pp. 253258. Recuperado de http://www.rinace.net/arts/vol5num5e/art34.htm

Arellano, G. (2007). Culturas juveniles y pedagogía en tiempos inciertos. Revista Colombiana de Educación, núm. 52, pp. 74-89. https://doi. org/10.17227/01203916.7695

Booth, T. y Ainscow, M. (2015). Guía para la educación inclusiva. Desarrollando el aprendizaje y la participación en los centros escolares. España: OEI/FUHEM.

Booth, T. y Ainscow, M. (2000). Índice de inclusión. Desarrollando el aprendizaje y la participación en las escuelas. Reino Unido: Center for Studies on Inclusive Education.

Booth, T., Ainscow, M. y Kingston, D. (2005). Index para la inclusión. Desarrollo del juego, el aprendizaje y la participación en educación infantil. Reino Unido: Center for Studies on Inclusive Education.

Echeita, G. (2013). Inclusión y exclusión educativa. De nuevo "voz y quebranto". Revista Iberoamericana sobre Calidad, Eficacia y Cambio en Educación, vol. 11, núm. 2, pp. 100-118. Recuperado de http://www.rinace.net/reice/numeros/ arts/vol11num2/art5.pdf

Elías, M. (2015). La cultura escolar: aproximación a un concepto complejo. Revista Electrónica Educare, vol. 19, núm. 2, pp. 285-301. http://dx.doi. org/10.15359/ree.19-2.16

Escolano, A. (2008). La escuela como construcción cultural. El giro etnográfico en la historiografía de la escuela. Espacios en Blanco. Revista de Educación, núm. 18, pp. 131-146. Recuperado de http://espaciosenblanco.unicen.edu. ar/pdf/numerorosanterior/Revista_Espacios_en_Blanco_N18.pdf

Feixa, C. (2010). Escuela y cultura juvenil. ¿Matrimonio mal avenido o pareja de hecho? Educación y Ciudad, núm. 18, pp. 7-18. Recuperado de https://revistas.idep.edu.co/index.php/educacion-y-ciudad/article/view/165/154

Fernández, T. (2004). De las "escuelas eficaces" a las reformas educativas de "segunda generación". Estudios Sociológicos, vol. 22, núm. 2, pp. 377-408. Recuperado de https://estudiossociologicos.colmex.mx/index.php/es/article/view/572/572

Frandsen, M. (2014). La tarea docente frente al proceso de (des) subjetivación a través de las culturas escolares. Diálogos Pedagógicos, vol. 12, núm. 23, pp. 75-84. Recuperado de http://revistas.bibdigital.ucc.edu.ar/ojs/index.php/ dialogos/article/view/1042/pdf

Gálvez, A. (2006). Motivación hacia el estudio y la cultura escolar: estado de la cuestión. Pensamiento Psicológico, vol. 2, núm. 6, pp. 87-101. Recuperado de https://revistas.javerianacali.edu.co/index.php/pensamientopsicologico/ article/view/51

Gentili, P. (2009). Marchas y contramarchas. El derecho a la educación y las dinámicas de exclusión incluyente en América Latina (a sesenta años de la Declaración Universal de los Derechos Humanos). Revista Iberoamericana de Educación, vol. 49, pp. 19-57. https://doi.org/10.35362/rie490673

Gutiérrez-Castro, F. A. (2015). Jóvenes, cultura escolar y comunicación. Magis, Revista Internacional de Investigación en Educación, vol. 7, núm. 15, pp. 97116. https://doi.org/10.11144/Javeriana.M7-15.JCEC 
Gutiérrez-Ortega, M., Martín-Cilleros, M. V. y Jenaro-Ríos, C. (2018). La cultura, pieza clave para avanzar en los centros educativos. Revista de Educación Inclusiva, vol. 11, núm. 2, pp. 13-26. Recuperado de https://revistaeducacioninclusiva.es/index.php/REI/article/view/325/355

Guzmán, E. (2015). Cultura escolar: reflexiones sobre su intervención desde una mirada sociocultural de la psicología educacional. Summa Psicológica, vol. 12, núm. 2, pp. 7-17. Recuperado de https://summapsicologica.cl/index. php/summa/article/view/264

Hongboontri, C. \& Keawkhong, N. (2014). School culture: Teachers' beliefs, behaviors, and instructional practices. Australian Journal of Teacher Education, vol. 39, núm. 5, pp. 66-88. http://dx.doi.org/10.14221/ajte.2014v39n5.7

Huergo, J. (2001). Desbordes y conflictos entre la cultura escolar y la cultura mediática. Nómadas, vol. 15, pp. 88-100. Recuperado de http://nomadas. ucentral.edu.co/nomadas/pdf/nomadas_15/15_7H_Desbordesyconflictosentre.PDF

Infante, M. (2010). Desafíos a la formación docente: inclusión educativa. Estudios Pedagógicos, vol. 36, núm. 1, pp. 287-297. Recuperado de http://www. rinace.net/rlei/numeros/vol6-num2/art8.pdf

Instituto Nacional para la Evaluación de la Educación (INEE) (2018). Condiciones básicas para la enseñanza y el aprendizaje en los planteles de educación media superior en México. Resultados generales. México. Recuperado de https://historico.mejoredu.gob.mx/wp-content/uploads/2018/12/ P1D247.pdf

Instituto Nacional para la Evaluación de la Educación (INEE) (2017). Directrices para la mejorar la permanencia escolar en la educación media superior. México. Recuperado de https://www.inee.edu.mx/wp-content/uploads/2018/12/ P1F105.pdf

Labajos, S., Gallego, B. y Lago, M. (2012). Factores de la cultura escolar que favorecen o dificultan la inclusión del alumnado de diversidad cultural. Propuestas para el plan de acogida. Tabanque Revista pedagógica, núm. 25, pp. 127-150. Recuperado de http://uvadoc.uva.es/bitstream/handle/10324/8966/Tabanque-2012-25-FactoresDeLaCulturaEscolarQueFavorecenODificultanL-4196707.pdf?sequence=1\&isAllowed=y

Lobato, X. y Ortiz , C. (2001). La importancia de la cultura escolar para la escuela inclusiva. Atención educativa a la diversidad en el nuevo milenio. XVIII Jornadas de Universidades y Educación Especial, pp. 677-684. Recuperado de https://ruc.udc.es/dspace/bitstream/handle/2183/11089/CC-63\%20 art\%2053.pdf?sequence=1\&isAllowed=y

López, N. (2005). Equidad educativa y desigualdad social. Desafíos de la educación en el nuevo escenario latinoamericano. Argentina: IIPE-Unesco. Recuperado de https://unesdoc.unesco.org/ark:/48223/pf0000142599

López, N., Opertti, R. y Vargas, C. (2017). Adolescentes y jóvenes en realidades cambiantes. Notas para repensar la educación secundaria en América Latina. Francia: Unesco. https://www.buenosaires.iiep.unesco.org/es/publicaciones/adolescentes-y-jovenes-en-realidades-cambiantes

Molina, W. y Sandoval, M. (2006). Cultura escolar y cultura juvenil: la (re)construcción simbólica del espacio escolar en la mutación cultural. Revista Temas Sociológicos, núm. 11, pp. 103-123. https://doi. org/10.29344/07196458.11.205 
Muñoz, D. (2009). Fronteras de la escuela y mundos de la vida juveniles: diálogos y tensiones entre culturas escolares y culturas juveniles. El Ágora USB, vol. 9, núm. 2, pp. 359-372. Recuperado de https://revistas.usb.edu.co/index. php/Agora/article/view/425/668

Murillo, J. y Krichesky, G. (2015). Mejora de la escuela. Medio siglo de lecciones aprendidas. Revista Iberoamericana sobre Calidad, Eficacia y Cambio en Educación, vol. 13, núm. 1, pp. 69-102. Recuperado de https://revistas.uam.es/ index.php/reice/article/view/2800

Organización de las Naciones Unidas para la Educación, la Ciencia y la Cultura (Unesco) (2015). Transformar nuestro mundo: la Agenda 2030 para el Desarrollo Sostenible. Asamblea General, sexagésimo noveno periodo de sesiones. Francia.

Organización de las Naciones Unidas para la Educación, la Ciencia y la Cultura (Unesco) (2009). Directrices sobre políticas de inclusión en educación. Francia. Recuperado de https://unesdoc.unesco.org/ark:/48223/pf0000177849_spa

Pérez-Gómez, Á. (2000). La cultura escolar en la sociedad neoliberal. España: Morata.

Pérez, M. y Quijano, R. (2010). La cultura escolar en los centros de secundaria: implicaciones del profesorado. Edetania, núm. 38, pp. 57-72. Recuperado de https://revistas.ucv.es/index.php/Edetania/article/view/298

Presidencia de la República (2019). Primer Informe de Gobierno 2018-2019. México: Gobierno de México. Recuperado de https://presidente.gob.mx/wpcontent/uploads/2019/09/PRIMER-INFORME-DE-GOBIERNO-2018-2019. pdf

Román, M. (2013). Factores asociados al abandono y la deserción escolar en América Latina: una mirada en conjunto. Revista Iberoamericana sobre Calidad, Eficacia y Cambio en Educación, vol. 11, núm. 2, pp. 33-59. Recuperado de https://revistas.uam.es/reice/article/view/2896

Secretaría de Educación Pública (SEP) (2012). Reporte de la Encuesta Nacional de Deserción en la Educación Media Superior. México: COPEMES-SEMSSEP. Recuperado de http://www.sems.gob.mx/work/models/sems/Resource/10787/1/images/Anexo_6Reporte_de_la_ENDEMS.pdf

Tenti, E. (2000). Culturas juveniles y cultura escolar. Argentina: IIPE-Buenos Aires. Recuperado de https://educiac.org.mx/pdf/Biblioteca/Juventud_e_Iden tidad/007CulturasJuveniles_y_CulturaEscolar.pdf

Valdez, E., Román, R., Cubillas, M. J. y Moreno, I. (2008). ¿Deserción o autoexclusión? Un análisis de las causas de abandono escolar en estudiantes de educación media superior en Sonora, México. Revista Electrónica de Investigación Educativa, vol. 10, núm. 1, pp. 1-16. Recuperado de https://redie.uabc.mx/ redie/article/view/183/319 